\title{
"Os vivos são sempre e cada vez mais governados pelos mortos": um estudo exploratório sobre desigualdades no morrer
}

\author{
"The living are always, and more \\ and more, governed by the dead": \\ study on the inequalities in dying
}

Stela N. Meneghel

Professora do Centro de Ciências da Saúde da Universidade do Vale do Rio dos Sinos

(Unisinos) e de Medicina da Universidade Luterana do Brasil (Ulbra) Caixa Postal, 111

94010-970 Gravatoé — RS Brasil

smeneghel@hotmail.com

Claídes Abbeg

Professora do curso de Pós-graduação em Saúde Coletiva (Ulbra)

Ronaldo Bastos

Coordenador do Núcleo de Informática Médica (Ulbra)

\begin{abstract}
Trata-se de uma investigação exploratória realizada em um cemitério de Porto Alegre, que serviu como prática de campo da disciplina de epidemiologia e sociedade, na pósgraduação em Saúde Coletiva da Universidade Luterana do Brasil (Ulbra), durante o primeiro semestre letivo de 1999. O objetivo da visita era observar as diferenças no morrer encontradas no Cemitério da Santa Casa da Misericórdia da cidade de Porto Alegre. As categorias analisadas foram: óbitos infantis; óbitos violentos; características epidemiológicas — gênero, profissão, cultura; pobreza/riqueza, incluindo mortes anônimas.

O objetivo do estudo é integrar aspectos históricos, artísticos e literários no entendimento da saúde/doença das populações, tornando o perfil sanitário das mesmas mais integral e abrangente.

PALAVRAS-CHAVE: desigualdade no morrer, arte cemiterial, processo saúde/doença

The present article consists of an exploratory investigation that took place in the cemetery of the city of Porto Alegre in a field trip for the course Epidemiology and Society of the postgraduation program in Collective Health at Universidade Luterana do Brasil in the first term of 1999. The visit to the cemetery aimed at observing differences related to death in Porto Alegre Cemitério da Santa Casa da Misericórdia.

The analyzed categories were children's deaths, violent deaths, epidemiological characteristics - gender, professional activity, education - and financial status, including anonymous deaths. The objective of the investigation is to integrate historical, artistic and literary aspects to better understand health and disease among the population and expand the sanitary profile we have of $i$.
\end{abstract}

KEYWORDS: unequal deaths, cemetery art, health/disease process. 
O dom de despertar no passado as centelhas de esperança é privilégio exclusivo do historiador convencido de que também os mortos não estarão em segurança se o inimigo vencer.

Walter Benjamin

$\mathrm{O}$ presente estudo relata uma investigação exploratória realizada em um cemitério da cidade de Porto Alegre. O trabalho fez parte da prática de campo desenvolvida durante a disciplina epidemiologia e sociedade, do curso de pós-graduação em Saúde Coletiva da Universidade Luterana do Brasil (Ulbra), durante o primeiro semestre letivo de 1999, e partiu dos referenciais teóricos clássicos utilizados pela epidemiologia acerca das desigualdades sociais no adoecer e no morrer.

Estudos que indicam os diferenciais entre as classes sociais, tanto na prevalência quanto nos diferentes tipos de patologias, fazem parte da epidemiologia desde a sua constituição como disciplina científica, em meados do século XVIII. Podem-se citar, por exemplo, as investigações sobre as epidemias de tifo na Silésia, realizadas e publicadas por Wirchow e Neumann, na Alemanha, durante o início do movimento da medicina social (Rosen, 1980). Na França, foi fundamental a contribuição de médicos sociais como Villermé (1988), indicando doenças que atingiam preponderantemente estratos populacionais desprivilegiados e extremamente depauperados pelas condições de trabalho criadas pela revolução industrial emergente.

Já no século XX, o movimento denominado epidemiologia social preocupou-se fundamentalmente em reafirmar a antiga assertiva de que as pessoas adoeciam de acordo com sua inserção de classe na sociedade. Foi elaborado o conceito de 'perfil epidemiológico de classe', considerado a expressão das vulnerabilidades no plano do biológico nas diferentes classes sociais (Breilh, 1990).

Laurell (1983) observou que, entre as tarefas da corrente médicosocial da medicina, encontra-se o encargo de demonstrar que a doença possui caráter histórico e social. Outro aspecto a ser relevado é a definição do objeto de estudo da saúde coletiva, de modo a permitir um aprofundamento na compreensão do processo saúde/doença e suas implicações sociais. Um último aspecto a se considerar é o da determinação social do adoecer humano. Em todos esses casos, é primordial o recorte dos grupos a estudar, de modo a possibilitar que se constatem as diferenças nos perfis patológicos nas classes que compõem a sociedade.

Estudiosos da saúde/doença nas populações têm evidenciado agudas diferenças na morbidade e na mortalidade das populações, assim como outras desigualdades. No Brasil, vários pesquisadores apresentam dados concretos que alertam para a precariedade das condições de saúde da população e para a desigual distribuição de riscos, doenças e morte. 
"A riqueza da epidemiologia está em não se aprisionar em um único modelo explicativo e buscar o conhecimento dos processos de intermediação que expliquem dentro de um marco de determinação social as flagrantes desigualdades nas probabilidades de adoecer e morrer de nossa população" (Loureiro, 1990).

A qualidade de vida determina e especifica a saúde. Constitui, portanto, um ponto chave da análise epidemiológica o impacto dos períodos que, como os de crise, acentuam processos sociobiológicos destrutivos (Breilh, 1990). Entender esse fenômeno em suas múltiplas dimensões não é tarefa fácil.

Pode-se citar algumas das teorias que buscam explicar as desigualdades em saúde. A teoria do artefato sugere que classe social e saúde são variáveis artificiais e sem determinação causal. A teoria da seleção natural coloca os mais pobres como os mais suscetíveis à enfermidade e à morte. A teoria materialista e estruturalista indica que as desigualdades em saúde decorrem das condições materiais e econômicas da população. Finalmente, a teoria culturalcomportamental acentua as diferenças que a conduta, os comportamentos e estilos de vida acarretam em relação ao processo de adoecer (Blane, 1997).

Tem-se buscado exaustivamente construir indicadores de saúde abrangentes, ou seja, parâmetros ou medidas que dêem conta de identificar de modo sensível, específico, econômico e factível o perfil sanitário das populações. Na realidade, a maioria dos indicadores utilizados é negativa, uma vez que não mede saúde, mas doença, morte e incapacidade. O olhar com que a saúde coletiva contempla a morte, no entanto, passa por um viés administrativo, em que a morte permanece neutra, abstrata, separada dos corpos que adoecem e dos rituais do morrer e do enterrar os mortos. Penetrar nos espaços sociais reservados à morte também foi objetivo deste trabalho.

A partir desse referencial teórico, os autores elaboraram uma proposta pedagógica prática. Ao referencial acrescentou-se uma referência obtida da leitura de uma entrevista com o escritor Caio Fernando Abreu. Nela, o autor relatava a prática de um professor de filosofia que iniciava o curso com visitas a cemitérios, objetivando diminuir a onipotência e o antropocentrismo inerente ao ser humano. Utilizou-se essa experiência como idéia inicial da pesquisa.

Com essa atividade, buscava-se qualificar a capacidade de observação do grupo de alunos, acurar o olho clínico, o olho imagético, características que se considera fundamentais para a qualificação de pesquisadores. Os alunos eram em sua maioria profissionais de área da saúde que exerciam suas atividades rotineiras de atenção à saúde no atendimento a pacientes em ambulatórios e hospitais. A proposta previa um distanciamento do campo habitual de práticas destes alunos, acreditandose que, dessa maneira, as pessoas estariam mais despidas de julgamentos a priori. Entrou-se no cemitério como grupo de cidadãos comuns, 
procurando deixar de lado as prerrogativas e as máscaras sociais, os títulos e os papéis sociais.

Outro objetivo da visita era observar as diferenças no morrer, no Cemitério da Santa Casa, evidenciadas em mausoléus, lápides, no estado de conservação dos jazigos, na idade, gênero e ocupação dos mortos, nas frases de despedida e em outros indícios que se julgassem relevantes. Procurava-se corporificar, individualizar e contextualizar as estatísticas de mortalidade.

No presente artigo, serão apresentados como resultados algumas das fotografias produzidas pelos alunos durante o processo de visita/ observação ao cemitério e serão selecionados alguns textos, observações, reflexões que acompanharam o trabalho, além da fundamentação teórica de aspectos históricos e sanitários relacionados.

\section{O uso antropológico da imagem}

A imagem fotográfica foi, desde que surgiu, o ponto de convergência de múltiplos discursos: técnico, estético, literário, filosófico, psicológico, semiológico, sociológico e antropológico. Seu uso na área da saúde tem sido crescente, sobretudo em imagens técnicas. Alguns autores têm procurado focalizar a fotografia não tanto como um objeto, mas como uma forma de ver e de pensar, ou seja, "uma maneira de ser no mundo, um estado do olhar e do pensamento" (Samain, 1998).

O uso da imagem envolve uma negociação entre autor e espectador, no sentido de construção/desconstrução. A imagem visual não é uma simples representação da realidade, mas um sistema simbólico. Ao contrário do que se pensa habitualmente, a imagem não significa restituição, mas sim reconstrução, ou seja, é sempre uma alteração voluntária da realidade que é preciso aprender a sentir e a ver (Leite, 1998).

A imagem precisa atravessar a oralidade e a escrita para poder constituir-se como elemento importante no entendimento do mundo. Nesse sentido, torna-se necessário lutar com o discurso científico oficial, no intuito de encontrar um espaço de reconhecimento e legitimidade. "Nos estudos de tradição européia e acadêmica, o texto verbal foi consagrado e tornou-se a forma prioritária de expressão ocidental e moderna. Os textos visuais, associados com maior freqüência ao conteúdo artístico e social, ficaram relegados à condição de ilustração dispensável ou superlativa" (Leite, 1998).

De qualquer maneira, o texto visual vem sendo redescoberto e exige o que, metaforicamente, se poderia chamar de alfabetização.

Fotografias apresentam o cenário no qual as atividades diárias, os atores sociais e o contexto sociocultural são articulados e vividos. Permitem elucidar comunicações não-verbais, relações espaciais entre pessoas e padrões de comportamento através do tempo. Imagens fotográficas retratam a história visual de uma sociedade, documentam 
situações, estilos de vida, gestos, atores sociais e rituais e aprofundam a compreensão da cultura material, sua iconografia e suas transformações ao longo do tempo. O uso da imagem acrescenta novas dimensões à interpretação da história cultural, permitindo aprofundar a compreensão do universo simbólico que se exprime em sistemas de atitudes relacionadas à morte, à riqueza, ao prestígio e ao status social, pelos quais grupos sociais se definem, identidades se constroem e mentalidades são apreendidas (Bittencourt, 1998).

O texto verbal e o visual são polissêmicos e complementares, sendo cada um mais adequado a determinados usos. Há necessidade de ler e distinguir criticamente as diferentes imagens como fonte de pesquisa ou de ensino em ciências sociais e mesmo na saúde.

Ler imagens significa classificar seus significados, entender seu sentido, atentar para o trajeto do olhar, as impressões visuais globais, as rupturas ou contradições entre o que é percebido e o que é compreendido. Isso é mais amplo do que uma simples leitura. A imagem não é um texto sem palavras, e ler imagens é sobretudo analisar esses signos e sua produção, desenredar as relações existentes entre os diferentes elementos, descobrir o latente atrás do aparente, o não visível através do visível (Peixoto, 1998).

\section{Os cemitérios de Porto Alegre}

Os relatos mais antigos com relação aos sepultamentos em Porto Alegre descrevem o terreno no qual se situou por muitos anos a antiga praça da Harmonia, às margens do rio Guaîba, como o local do primeiro cemitério na primitiva povoação do Porto dos Casais, fundada pelos açorianos (Coruja, 1983; Franco, 1993).

A partir do ano de 1772, os sepultamentos passaram a ocorrer no cemitério da Igreja matriz e inclusive dentro da própria igreja. O cemitério estendia-se desde os fundos da antiga matriz, na rua Duque de Caxias, até a rua do Arvoredo, hoje Coronel Fernando Machado. Nos terrenos da Igreja das Dores também foram sepultados diversos irmãos da antiga ordem religiosa. Porém, a principal necrópole da época foi a da Igreja da Matriz, que chegaria superlotada ao ano de 1850. Não tardou que esse cemitério fosse envolvido pela expansão da vila, passando a gerar repetidas preocupações de natureza sanitária. Em 1801, lê-se em ata da Câmara que "se escreveu uma carta ao vigário desta freguesia para não se enterrarem corpos nesta matriz por um tempo de seis meses, pela representação que esta Câmara fez ao cirurgião-mor pela epidemia que tem havido" (Franco, 1993).

Esses episódios são contemporâneos a várias epidemias que ocorreram na cidade no século XIX. Uma delas, que assolou a província de Rio Grande em 1855, ocasionou a mortandade de $10 \%$ da população de Porto Alegre, principalmente de escravos e setores mais pobres, cujas condições sanitárias eram deploráveis. Foram tomadas várias 
medidas sanitárias, inclusive matança e enterramento de cães vadios. Em 1874, ocorreu uma epidemia de varíola na capital. As atas da Câmara Municipal apresentam várias resoluções para combate à epidemia. Uma das mais curiosas foi a resolução dos vereadores de queimar alcatrão em volta da cidade, para desinfetar o ar.

No início do século XIX, a cidade de Porto Alegre possuía 3.927 habitantes e apenas uma enfermaria, que abrigava os doentes com verbas da caridade pública. A necessidade da criação de um hospital era evidente, sobretudo para tratar a população carente, e não foi difícil obter a concessão para se abrir um hospital de caridade. A pedra fundamental foi lançada em 1803, e a inauguração das primeiras enfermarias deu-se em 1826.

Surgiu assim a Santa Casa de Misericórdia, no início com uma função muito mais assistencial que terapêutica, de acordo com os estatutos das instituições portuguesas congêneres, pelas quais se regia. Sua finalidade principal era dar atendimento aos pobres — na doença, no abandono e na morte - abrigando além dos enfermos, os abandonados, crianças e velhos, os separados, criminosos, doentes e os excluídos do convívio social, como os doentes mentais (Mauch, 1994).

Um dos objetivos da Santa Casa era dar abrigo aos mortos através da construção do cemitério.

Por volta de 1840, o cemitério da antiga matriz encontrava-se completamente lotado, não se observando as normas sobre profundidade das covas e sobre o espaço intermediário entre elas. Além disso, não havia indicações sobre a data das inumações, o que levava a serem desenterrados cadáveres ainda em estado de putrefação. Quando o barão de Caxias, na época presidente da província, publicou seu relatório anual de 1846, fez citações alarmantes com relação ao antigo cemitério, ao qual não faltavam "a porta da sacristia fechada, cadáveres de escravos mal amortalhados e foçados pelos cães errantes" (Franco, 1993). Em certo trecho afirmava ele: "tão pequeno cemitério mas apinhado de cadáveres, cuja exalação, tão sensível ao olfato em dias calorosos, era quase suficiente para pejar o ar de partículas deletérias". E concluía: "para extinguir o escândalo e esse foco de miasmas, não julguei dever esperar mais. Fiz com que a Santa Casa se incumbisse da edificação de um novo cemitério fora da cidade, em lugar escolhido por uma comissão de pessoas entendidas." Foi nessa época que se designou o local denominado Alto da Azenha para abrigar o novo cemitério (Arquivo Histórico do RS, 1846).

No Rio Grande do Sul, durante o Segundo Reinado (1840-89), a nobreza local, cujos jazigos encontram-se no Cemitério da Santa Casa, não reafirmou o seu status social com túmulos monumentais, ao contrário da aristocracia do restante do país. 
O apogeu da arte funerária em Porto Alegre aconteceu entre 1900 e 1940, período de expansão industrial, comercial e econômica da cidade e do apogeu do governo positivista de Júlio de Castilhos, também denominado ditadura científica positivista. Fazia parte do pensamento do governo positivista desta época o patrocínio de monumentos públicos e jazigos monumentais, entre os quais se podem citar os monumentos funerários de Júlio de Castilhos, Pinheiro Machado e Otávio Rocha. Em geral, essas sepulturas foram financiadas pelo governo estadual, por corporações e entidades empresariais. Na primeira metade do século, era usual que, em torno destes mausoléus, existisse um verdadeiro culto cívico.

O Cemitério da Santa Casa representa um verdadeiro museu ao ar livre, com mais de trezentas estátuas de valor significativo e que, segundo Bellomo (1988), podem ser classificadas em três grupos: tipologia cristã, com seus anjos, santos, crucifixos e pietás; tipologia alegórica, com representações de sentimentos (desespero, dor, consolo) e princípios religiosos (fé, coragem, esperança); e, finalmente, tipologia cívico-celebrativa, enaltecendo-se personagens do mundo político.

Após 1940, com a mudança dos padrões sociais e o declínio da ideologia positivista, inicia-se a decadência da arte cemiterial, que quase atinge a paralisação, depois de 1950.

\section{Método}

O local selecionado para a realização da visita de estudo foi o Cemitério da Santa Casa da Misericórdia, localizado no bairro Azenha, na cidade de Porto Alegre. Participaram da visita ao cemitério 48 alunos e dois professores.

Solicitou-se que cada um dos alunos documentasse fotograficamente as particularidades relevantes relacionadas às desigualdades no morrer, bem como desenvolvesse conclusões pessoais sobre o observado, selecionando a(s) foto(s) que julgasse mais expressiva(s). Anteriormente à observação, trabalhara-se com questões referentes às desigualdades no morrer, aos rituais fúnebres e ao processo de enterramento dos mortos. Não havia roteiro prévio, apenas a solicitação anterior e a máquina fotográfica.

As fotografias foram utilizadas neste estudo como fonte de dados e elemento para observação, procurando-se fugir de modelos tradicionais de elaboração de trabalhos calcados apenas na linguagem oral. Tentouse uma aproximação da técnica denominada 'investigação social fotográfica', que compreende: levantamento fotográfico, pesquisa iconográfica em arquivos institucionais ou particulares, gravação de fotos, tomadas fotográficas, pré-edição e edição (Gallano, 1998).

Como resultado da pesquisa, serão apresentadas algumas das fotografias produzidas pelos alunos durante o processo de visita/ 
observação ao cemitério e foram selecionados alguns textos, observações e reflexões que acompanharam o processo.

Os resultados foram expostos, discutidos e comentados em sala de aula, acrescidos das observações trazidas do trabalho prático. O processo foi complementado por uma sessão de fotografias históricas de logradouros, cemitérios e instituições de saúde da cidade de Porto Alegre.

As fotografias que haviam sofrido uma primeira triagem e seleção por parte dos alunos foram escrutinadas pelos investigadores, em busca de categorias explicativas. Algumas delas foram consideradas representativas, eram temas presentes em diferentes trabalhos. Selecionaram-se as seguintes categorias: óbitos infantis; óbitos violentos; óbitos em que ficou evidente alguma característica demográfica ou cultural — gênero, profissão, etnia; pobreza/riqueza, incluindo mortes anônimas; e monumentos funerários de figuras históricas.

As fotos foram correlacionadas a citações, frases de despedida e dizeres característicos e ao contexto histórico, político e sanitário da época. Os textos foram extraídos das próprias lápides, onde cumpriam a função de expressar sentimentos de luto, despedida, enaltecimento de características e virtudes do morto. Além disso, houve um espaço para expressão dos sentimentos, emoções e percepções dos alunos visitantes.

\section{"Os vivos são sempre e cada vez mais governados pelos mortos"}

Todas as sociedades desenvolvem um ou mais sistemas fúnebres pelos quais pode se entender a morte em seus aspectos pessoais e sociais. Em muitas culturas, a noção de dar aos mortos uma boa despedida é um tema proeminente. Isso pode incluir o gasto de grandes somas em dinheiro em um caixão luxuoso, com o morto adereçado com roupas de luxo, jóias e maquiagens. Depois do advento da fotografia, tornou-se hábito entre a classe dominante fotografar o morto. A tradição foi incorporada pelas classes populares, nas quais ela ainda está viva. Veja-se, por exemplo, o sensível texto de Koury (1999), acerca do processo de luto de uma mulher nordestina pelo filho morto tragicamente: "O retrato do meu filho vivia no meu peito. Na foto parece que meu menino está rodeado de luz..."

De qualquer maneira, o funeral é percebido como um reflexo das realizações da vida do indivíduo e um conforto para os vivos. O sistema mortuário é o meio que a sociedade encontra de reconstituir sua integridade após a perda de um dos membros.

Na visita exploratória, foram produzidas mais de cem fotos, das quais 15 encerravam situações consideradas representativas.

Antes de analisar as categorias propriamente ditas, comentemos a foto 1. Trata-se do portão de uma capela mortuária, adornado pela figura de dois anjos. Desde tempos imemoriais, ao penetrar nos umbrais 
da morte, fazia-se necessária a presença protetora de um guardião, um acompanhante. Hermes, na Grécia, fazia o papel do deus mensageiro, o daimon, guia das almas pelos mundos inferiores, espírito protetor, sábio, guardião dos mistérios do outro lado. "Anjos protetores, dêemnos o acesso" poderia ser a legenda desta foto. A expressão Revertere ad locum tuum sinaliza o pórtico de entrada do cemitério da Santa Casa de Porto Alegre.

No Cemitério da Santa Casa de Misericórdia da cidade de Porto Alegre encontram-se os jazigos de muitas figuras históricas do estado do Rio Grande do Sul. Diversos desses túmulos foram construídos durante o governo positivista de Júlio de Castilhos, pois fazia parte do pensamento oficial a celebração cívica dos líderes políticos vinculados ao grupo dominante. Os jazigos e monumentos pertencentes à tipologia cívico-celebrativa, além de servirem como sepultura, celebravam as memórias dos vultos destacados do mundo político.

As doutrinas positivistas chegaram ao Rio Grande do Sul através da influência dos militares que cursavam a Escola Militar do Rio de Janeiro, no final do século XIX, em que a pregação dirigida por Benjamin Constant era intensa. Entre os prosélitos, desatacou-se a figura de Júlio de Castilhos, identificado com as premissas republicanas, antiliberais, tradicionalistas, patriarcais e anti-socialistas, combinando o caráter autoritário do positivismo com o caudilhismo rio-grandense, que possivelmente exacerbou a doutrina positivista (Bellomo, 1993).

A doutrina positivista surgiu no século XIX, criada e divulgada por Auguste Comte e caracterizada como uma filosofia burguesa liberal, ao mesmo tempo conservadora e progressista. Dentro das premissas da doutrina, a humanidade está em permanente evolução em direção ao progresso, porém dentro de uma ordem preestabelecida, cujas infrações são percebidas como negativas. Por isso, o positivismo é antirevolucionário.

Havia uma opção pela ditadura republicana, percebida como única forma de governo capaz de atingir os objetivos propostos. O indivíduo só existiria no coletivo. O artista, portanto, deveria conferir aos líderes da comunidade a imortalidade da arte, que teria como objetivo aprimorar o caráter dos indivíduos, por meio da educação moral, da exaltação da coragem, da prudência e da firmeza. Assim, o positivismo pensava atingir a moralização das instituições e fornecer às gerações futuras elementos morais, através de figuras exemplares (idem).

Júlio de Castilhos governou o estado do Rio Grande do Sul no período de 1893 a 1897 e foi um dos fundadores e dirigentes do Partido Republicano Rio-Grandense, de orientação positivista, no qual exerceu uma verdadeira ditadura. A revolução federalista (1893-95) representou a transição da monarquia para a república, no Rio Grande do Sul, e refletiu a individualidade histórica de homens em luta pelo poder regional. Na prática, o caudilhismo substituiu a antiga nobreza imperial. 
A revolução federalista foi uma das mais sangrentas da história do estado, travada entre duas facções: liberais federalistas (maragatos) e republicanos positivistas (chimangos). O conflito, apesar da participação das classes populares, revelou-se antes de mais nada intra-oligárquico. A prática da violência nessa disputa, que normalizou a degola e outras formas brutais de eliminação de adversários, não foi isolada, mas uma decisão política, sintonizada com o terror organizado no sentido jacobino do termo, cujas repercussões e bipolaridade fazem-se sentir até hoje na história do estado (Flores, 1993).

Júlio de Castilhos morreu em 1903, e seu túmulo, construído pelo escultor Décio Vilares, é formado por uma pirâmide com uma águia no topo, contendo a inscrição "A Júlio de Castilhos, o Rio Grande do Sul" e a máxima positivista "Os vivos são sempre e cada vez mais governados pelos mortos". Além disso, ele põe em evidência o escudo do estado e o lema Ordem e Progresso. Na base da pirâmide, uma moça sentada representa a pátria, segurando na mão direita a bandeira nacional e, na esquerda, uma coroa de louros e o escudo do Rio Grande do Sul (fotos 2 e 3).

Ao lado do jazigo de Júlio de Castilhos foi erigido o monumento funerário ao senador Pinheiro Machado, líder republicano gaúcho pertencente à mesma facção de Castilhos, assassinado em 1915, no Rio de Janeiro. Esse monumento constitui o maior grupo escultórico da arte funerária no estado (foto 4).

O sepultamento do senador, organizado pelo governo de Borges de Medeiros, foi uma verdadeira apoteose positivista. O túmulo, obra do escultor Rodolfo Pinto, é considerado o mais monumental de Porto Alegre. Representa Pinheiro Machado sobre um leito romano, coberto pela bandeira nacional, tendo ao lado a pátria, representada por uma jovem com um barrete frígio, fazendo um gesto protetor. Aos pés do leito, uma mulher representa Clio, a musa da história, registrando a vida do morto em seu livro e apontando o herói celebrizado como exemplo para as novas gerações, simbolizadas por um grupo de crianças. Baixos-relevos mostram cenas de culto cívico e a marcha da humanidade. Um dos baixos-relevos mostra um casal realizando um ritual cívico no altar da pátria. Outro mostra uma procissão de figuras desnudas em torno da palavra imortalidade (Bellomo, 1993).

O conjunto tumular foi concebido ideologicamente dentro do espírito positivista, utilizando a simbologia alegórica típica dessa corrente de pensamento. A imortalidade é percebida como a conservação da memória do líder morto, símbolo e modelo para as gerações futuras. Estes monumentos, sem dúvida, corporificam um dos lados da desigualdade - o morrer da classe dominante.

Os pesquisadores visitantes produziram uma quantidade expressiva de imagens sobre as desigualdades. Mostraram-se sensibilizados com a morte dos pobres ou a pobreza do morrer. "Os homens pobres enterram seus anjos com um pano qualquer, quando o possuem... mais uma 
cruz feita com paus achados na estrada e rezas de uma tristeza alegre pela sorte de não seguir o destino que outros tantos estão tendo de suportar" (Koury, 1998).

Ao observar, com consternação, o campo santo do Cemitério da Santa Casa, o único cemitério que acolhe pobres em toda a capital do estado, escondido atrás dos monumentos funerários das figuras ilustres, não foi possível deixar de constatar, no concreto, as desigualdades no morrer (foto 5). Um quadrado nu de terra vermelha, semeado e tornado a semear de cruzes. O enterramento gratuito dos corpos tem uma permanência estipulada de três anos, período mínimo necessário para proceder à exumação de cadáveres, de acordo com o artigo 311 do Decreto Estadual n 23430 (Código Sanitário Estadual), de 24 de outubro de 1973, referente a cemitérios públicos e privados do estado. As sepulturas no chão batido, identificadas por uma cruz de ferro e uma placa com o número, lembram um campo de batalha e de miséria. Não há fotos ou nomes. "Campo santo", lugar dos pobres. Os enfeites são garrafas plásticas, flores plásticas, velas.

Brum (1999, p. 36), em matéria publicada sobre "enterro de pobre", observa, recortando o depoimento de um homem que acabara de enterrar o filho morto no campo santo da Santa Casa, entre as duas mil cruzes dispostas como em um campo de guerra: "Não há nada mais triste que enterro de pobre, porque o pobre começa a ser enterrado em vida." A autora denuncia as condições de vida e de morte de contingentes da população, cuja sina "é uma cova rasa, para facilitar o despejo do corpo quando vencerem os três anos de prazo, um caixão doado, em um cemitério de lomba, e esse episódio tem acontecido sucessivamente por mais de quinhentos anos".

Durante as visitas, foram encontrados vários túmulos de crianças. É a mortalidade infantil com uma cara e um nome. Os primeiros registros sobre a mortalidade infantil em Porto Alegre estão associados à roda dos expostos da Santa Casa da Misericórdia, semelhante a outras rodas descritas em outras regiões do Brasil. Na roda era colocada a criança enjeitada, preservando-se o anonimato do depositário. Após a Lei do Ventre Livre, aumentou o número de crianças negras abandonadas na roda dos expostos, porque ao senhor não interessava sustentar uma criança liberta. A mortalidade infantil nesse grupo de crianças era mais elevada do que entre crianças brancas.

A mortalidade infantil na cidade de Porto Alegre apresentava cifras altíssimas nos primórdios do século XX: 221,3 óbitos/1.000 nascidos vivos em 1900, 185,0/1.000, em 1910, e 279,0/1.000, em 1920 (Bonow, 1979). Os índices representam aproximadamente vinte mortes para cada cem crianças menores de um ano e correspondem a um nível de saúde bastante precário. Os coeficientes de mortalidade infantil no município de Porto Alegre apresentavam valores maiores que os do estado (1900: 118,19; 1910: 115,8; 1920: 90,0/1.000 nascidos vivos), presumivelmente pelos índices maiores de sub-registro no interior da 
província. A mortalidade infantil mostra comportamento descendente no Rio Grande do Sul e na capital, porém as populações de menor renda apresentam taxas maiores do que a população em geral (Barcellos, 1986; Fischmann, 1980).

Na visita exploratória ao cemitério, foram observados túmulos de bebês nascidos e mortos no mesmo dia, muitas vezes fotografados para o ritual fúnebre, de acordo com os ditames culturais, ou para guardar alguma lembrança da vida ainda não vivida. Eram crianças de famílias mais abastadas, porque o bebê do pobre não tem nome nem retrato.

As desigualdades de gênero ficaram evidentes nos jazigos de família, onde aparece apenas 'senhor Fulano e esposa', seguido pelo sobrenome do marido. Mulheres que entraram na morte sem um nome próprio, identificadas e nomeadas a partir da ótica patriarcal. "O patriarcado não sucumbe nem na morte", afirmou uma das alunas. Mulheres descritas no jazigo segundo atributos e características dos papéis de gênero: 'esposa', 'colaboradora inteligente', 'companheira na vida e no silêncio da eternidade' de homens adjetivados como 'estrela', 'prócer' e outras qualificações. Este fato tem sido documentado por historiadores que afirmam conhecer a mulher romana através das inscrições mortuárias, criadas por seus maridos e filhos (Chauí, 1984).

Durante os anos do castilhismo, as mulheres foram estigmatizadas e relegadas aos tradicionais papéis estereotipados de esposas e mães. A ditadura científica positivista de Júlio de Castilhos entendia o papel da mulher restrito ao espaço doméstico, guardiã da honra da família, reclusa no lar, para evitar as tentações do mundo exterior. Desprovida de libido, devia permanecer fiel ao marido, mesmo depois da morte deste, responsável pela preservação da memória da família e elo de ligação entre os vivos e os mortos. Essa misoginia do positivismo contraria a trajetória da mulher rio-grandense, pelo menos as das classes mais abastadas, que, naquela época, já usufruíam de uma relativa independência. Mulheres que administravam sozinhas estâncias e propriedades, durante os constantes conflitos que permearam o Rio Grande no século XIX.

Além dessa posição em relação ao gênero, os positivistas expressaram opiniões conservadoras em relação à saúde pública. Acusaram a higiene oficial de despótica, de arrancar os filhos às mães para lançá-los em hospitais insalubres, de devassar a propriedade alheia com desinfecções e outras medidas sanitárias. Os castilhistas lideraram a luta antivacinação, em oposição às medidas adotadas por Oswaldo Cruz durante o governo Rodrigues Alves. Segundo o apostolado antivacina, apoiado pelo governo positivista de Borges de Medeiros, eles apostrofavam que "o materialismo médico nada respeita, nem o pudor, nem o respeito devido à delicadeza feminina, nem a bondade para com as crianças, nem o respeito à velhice" (Singer, 1981). 
Nos jazigos do cemitério da Santa Casa observa-se um uso constante de alegorias femininas, algumas de inspiração neoclássica: a justiça, a pátria, a desolação. Também aparecem as figuras femininas de cunho religioso: virgens, anjos, pietás. A cidade de Porto Alegre, representada por uma mulher, aparece no jazigo monumental de Otávio Rocha. As alegorias representadas na foto 6 encontra-se no jazigo da família Chaves Barcellos.

A inserção social do indivíduo aparece não somente no luxo e na ornamentação dos jazigos, mas também na descrição das honrarias que o morto adquiriu em vida. Foram arrolados honrarias militares e políticas, títulos de bravura e nobreza, excelência no desempenho de atividades burguesas.

As mortes violentas também se fizeram visíveis. No início do século $\mathrm{XX}$, predominavam os assassinatos, atualmente predominam os acidentes. Essas mortes produzem um agudo sentimento de injustiça nas famílias vitimadas, que utilizam o jazigo como espaço de denúncia. No mausoléu de José Plácido de Castro, gaúcho fundador do estado do Acre e morto em 1908, em crime que ficou impune, celebra-se o morto e denuncia-se o sistema político vigente. A justiça, de olhos desvendados, empurra a balança com uma espada, em cujo prato há um saco com dinheiro. Há ainda um leão flechado pelas costas, alusão à morte por traição. As inscrições tumulares denunciam a impunidade do crime (foto 7).

Plácido de Castro, rio-grandense partidário da corrente que seguia as idéias de Gaspar Silveira Martins, liberal federalista, opositor de Júlio de Castilhos, mudou-se para o Acre, após a derrota da revolução federalista, onde assumiu o comando dos acreanos rebelados contra o governo boliviano e contra a entrega da região a um grupo angloamericano. Em 1902, iniciou-se uma rebelião, e Plácido de Castro atacou os bolivianos em Xapuri (local do conflito com Chico Mendes, um século mais tarde) proclamando o estado independente do Acre. Após alguns meses, os brasileiros conquistaram todo o território do Acre e promoveram a rendição da Bolívia. Plácido de Castro, figura de grande prestígio junto à população, foi prefeito da região do Alto Acre. Morreu assassinado em 1908 (Lacombe, 1979).

A morte de Plácido de Castro foi um crime de natureza essencialmente política, "um magnicídio com todas as suas características. O prestígio que desfrutava junto ao povo, opondo embargo ao despotismo dos elementos oficiais terão aconselhado sua eliminação, na impossibilidade de afastá-lo do Acre" (Goycochea, 1973). A justiça nunca se manifestou sobre o crime, embora tenha sido identificado o grupo assassino, com mandantes vinculados à polícia local.

A foto 8 pode ser considerada um contundente documento da categoria violência. O chamamento "Assassinado!" acompanha o nome do morto e a data do óbito. 
As frases de luto, de despedida, de desconsolo, plasmadas em metal, nas figuras de pequenos anjos, na estatuária, poderiam constituir por si só um trabalho em separado. "Rio-Grandenses, podeis confiar: este velho soldado há de servir a vossa terra com a certeza de que amanhã, ao rememorardes esta etapa da vossa vida política, sereis forçados a dizer que ele foi sempre um homem de bem", é a frase que adorna o mausoléu do general Daltro Filho, interventor no estado do Rio Grande do Sul, nomeado por Getúlio Vargas, o primeiro túmulo em que aparece a figura de um gaúcho vestido com trajes típicos.

Foram coletadas frases ao acaso, de acordo com a sensibilidade dos alunos fotógrafos. Também foram documentadas situações modestas, túmulos tão pobres que a identificação do morto estava pichada com pincel atômico. Frases dispostas em bilhetes, lembretes, corações de cartolina, flores de papel, despedida sem consolo.

A exploração do cemitério - aspectos históricos, artísticos, humanos - trouxe assombro e consternação ao grupo, que pôde acrescentar às concepções teóricas dos indicadores de saúde (e de morte) um nome, um retrato, uma alegoria, uma figura, uma família, um anjo, um epitáfio. Muitos outros veios poderiam ser seguidos, mas isso extrapolaria o objetivo e o tempo da visita.

\section{Conclusão}

A realização deste trabalho possibilitou a integração, em uma mesma disciplina, de aspectos interdisciplinares pertencentes aos campos da epidemiologia, da antropologia, da história, da arte cemiterial. Aguçou o olhar observador do pesquisador, propiciou discussões, leituras e releituras do material visual — polissêmico, simbólico, metafórico. Modificou posturas, sacudiu máscaras, fez brotar interrogações. Mostrou que o material iconográfico pode ser usado não só pelas ciências sociais, mas também pelas ciências da saúde, e até pela epidemiologia.

Além disso, ofereceu a oportunidade para que se fizessem interessantes observações, demonstrando que as diferenças entre classes sociais observadas em vida pela epidemiologia permanecem na morte, identificadas pela antropologia.

Pretende-se estender estas visitas exploratórias - etno-epidemioartístico-culturais - a outros locais de interesse histórico/sanitário, como, por exemplo, o Hospital Psiquiátrico São Pedro, monumento arquitetônico do estado do Rio Grande do Sul, um dos primeiros asilos para alienados construídos no Brasil, e o Hospital Colônia Itapoã, antigo leprosário, localizado às margens do rio Guaíba.

A leitura de imagens, aspecto descurado nos cursos de metodologia, pode constituir um elemento a mais na construção de perfis de saúde/ doença. 
"OS VIVOS SÃO SEMPRE E CADA VEZ MAIS GOVERNADOS...

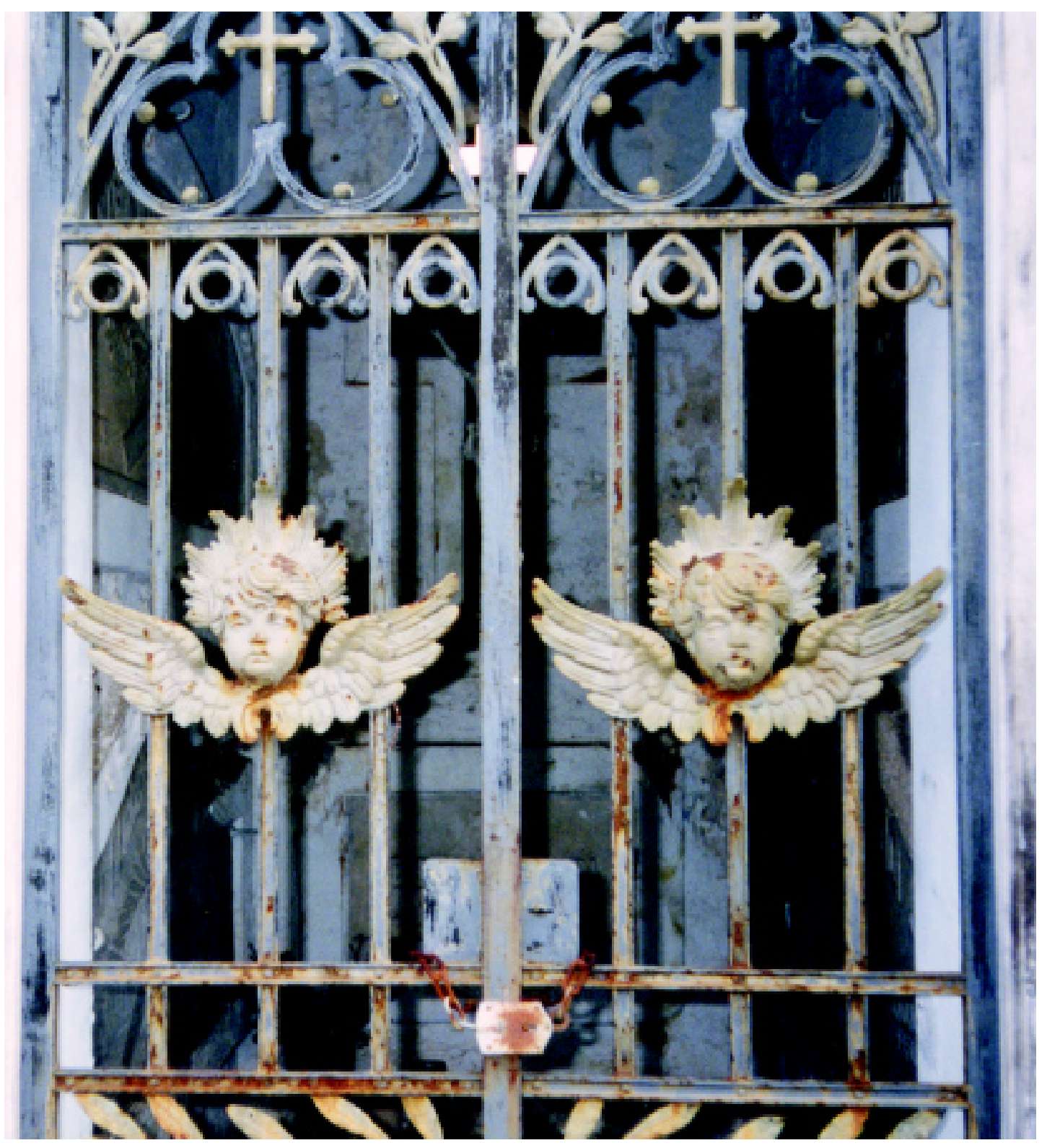

Foto 1 - Portão de capela mortuária (Carmem Nudelmann). 
STELA N. MENEGHEL, CLAÍDES ABBEG E RONALDO BASTOS

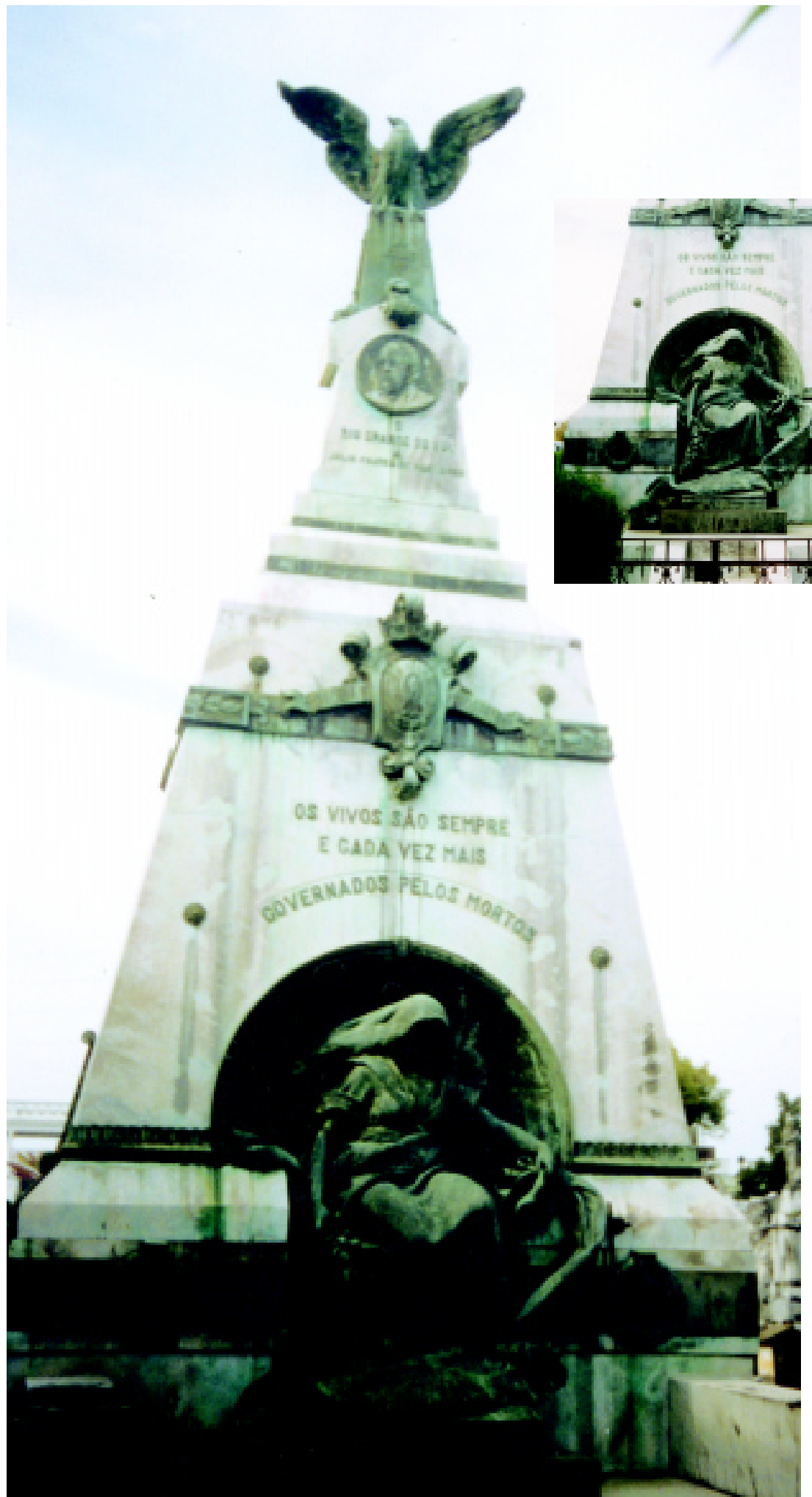

Fotos 2 e 3 - Túmulo de Júlio Castilhos que traz na lápide a máxima "Os vivos são sempre e cada vez mais governados pelos mortos” (Stela Meneghel).
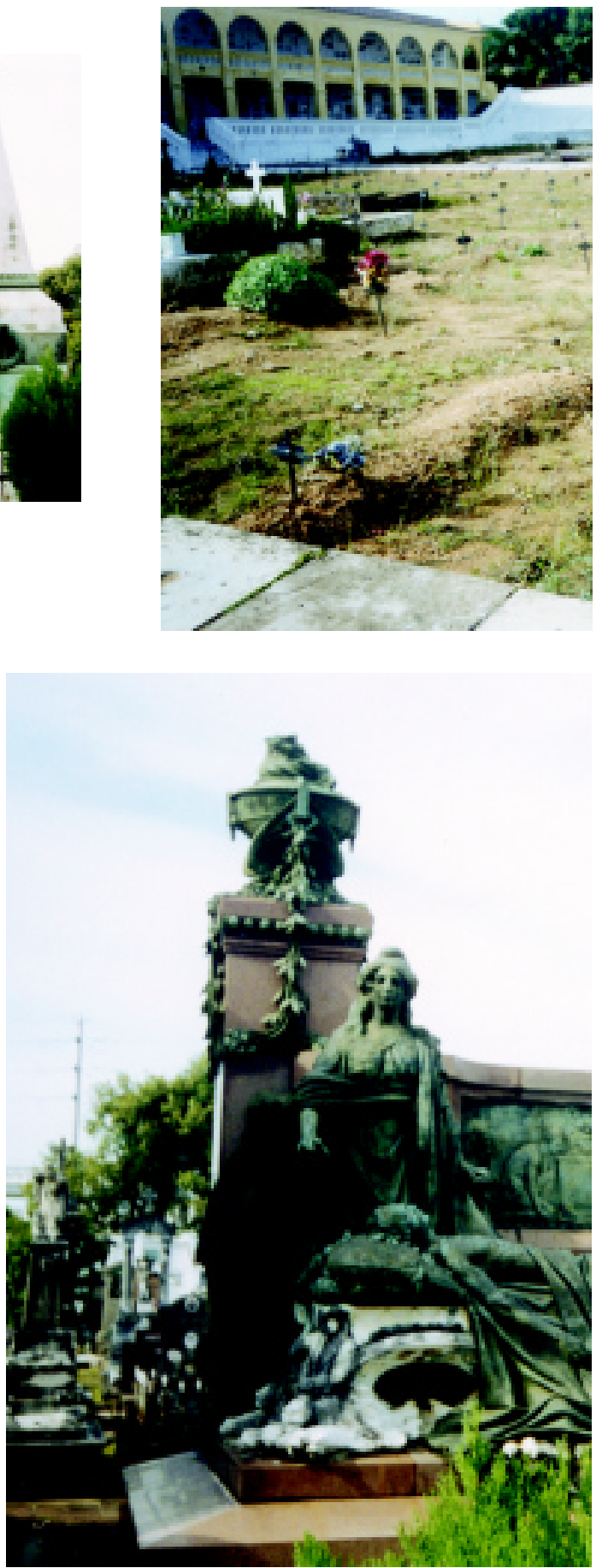

Foto 4 - Monumento funerário ao

Senador Pinheiro Machado (Míriam Brew). 
Foto 5 - Campo Santo, área

destinada aos pobres no

cemitério da capital gaúcha

(Andrea de Melo).
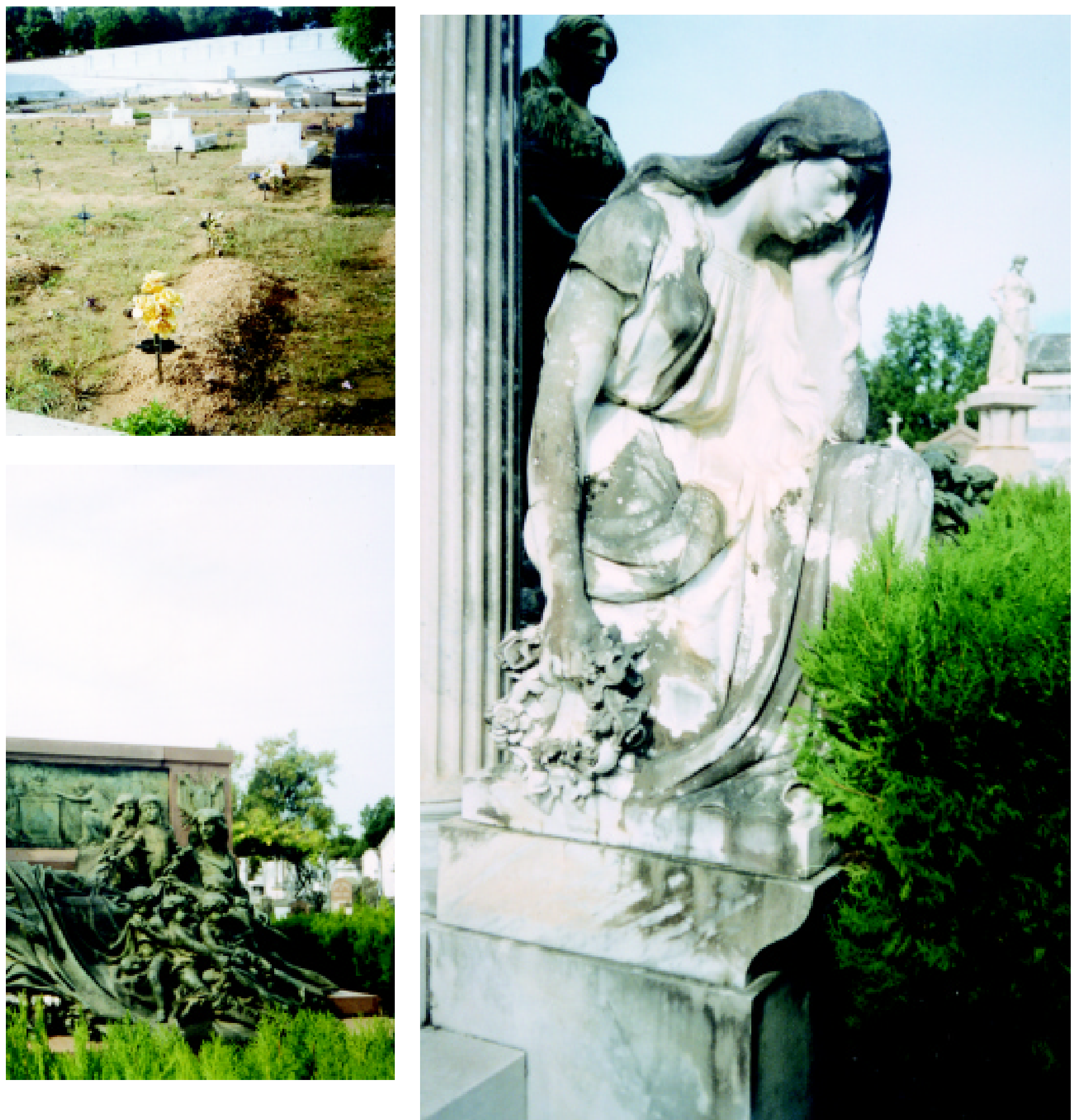

Foto 6 - Jazigo da família Chaves Barcellos (Stela Meneghel). 


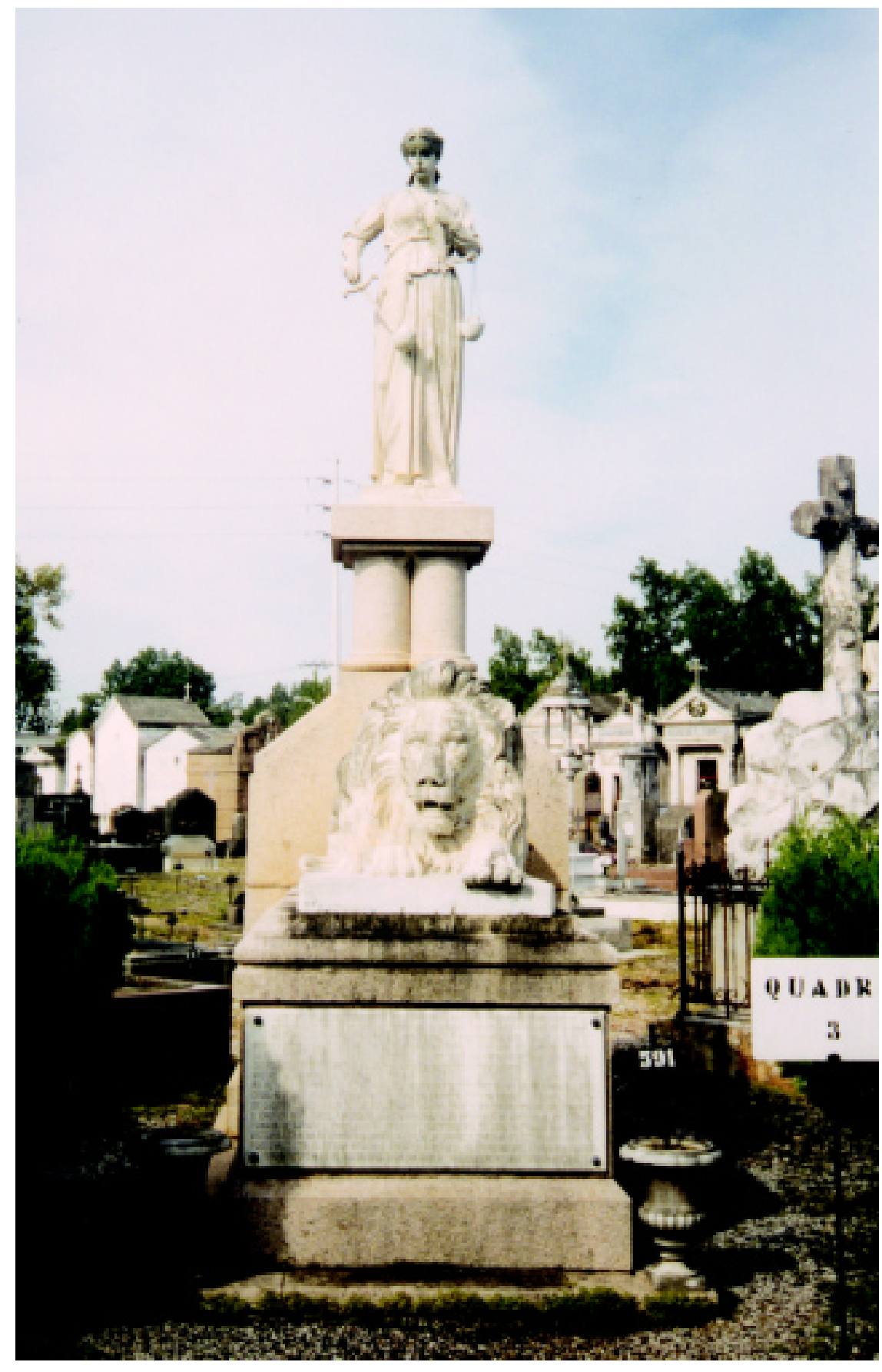

Foto 7 - No mausoléu de José Plácido de

Castro, gaúcho

fundador do estado do Acre que foi assassinado em 1908, a justiça empunha a balança com uma espada, em cujo prato há dinheiro

(Stela Meneghel).

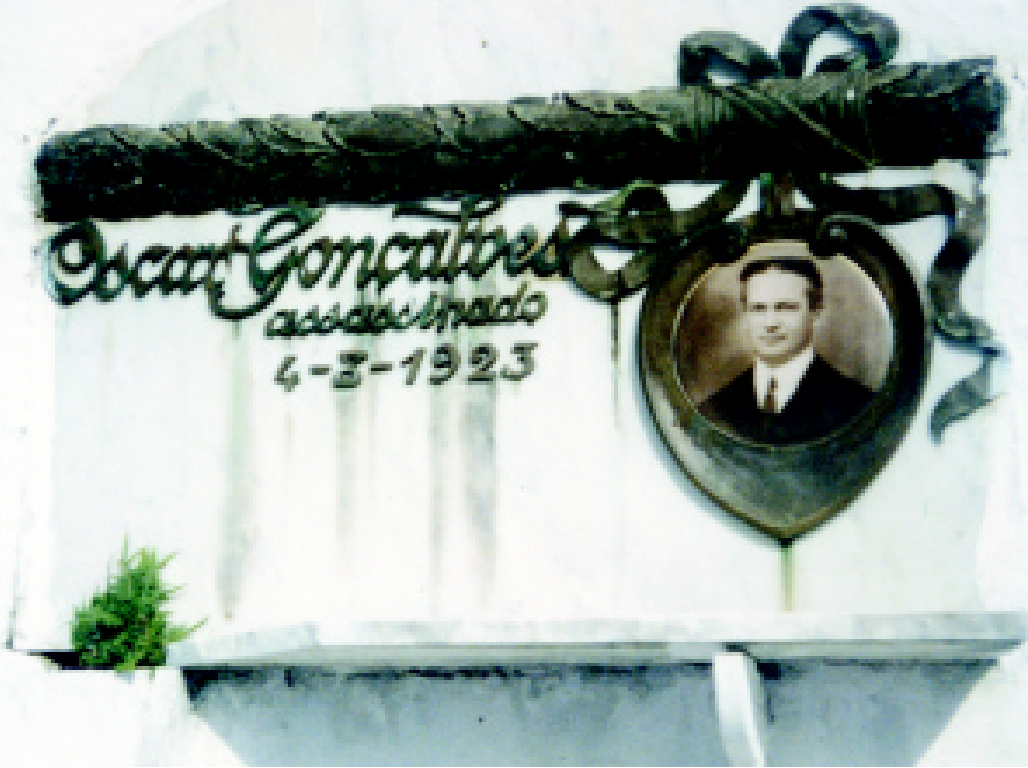

Foto 8 - Junto ao nome do morto há o Registo de que foi assassinado (Yolanda da Silveira). 


\section{REFERÊNCIAS BIBLIOGRÁFICAS}

Arquivo Histórico do Rio Grande do Sul 1846

Barcellos, T. et alii 1986

Bellomo, H. R. 1993

Bellomo, H. R. 1988

Bittencourt, L. A. 1998

Blane, D.

Bonow, G. M. 1979

Breihl, J. 1990

Brum, E. 26.6.1999

Chauí, $M$. 1984

Coruja, A. A. P. 1983

Fischmann, A. et al. 1980

Flores, E. C. 1993

Franco, S. C. 1993

Gallano, A. M. 1998

Goycochea, C. 1973

Koury, M. G. P. 1999

Koury, M. G. P. 1998

Lacombe, A. J. 1979

Laurell, A. C. 1983
Relatório provincial do barão de Caxias do ano de 1846. Porto Alegre.

Segregação urbana e mortalidade em Porto Alegre. Porto Alegre, Fundação de Economia e Estatística.

'Revolução, lideranças e escultura funerária no Rio Grande do Sul'. Em M. Flores (org.), 1893-1895: a revolução dos maragatos. Porto Alegre, Edipuc-RS.

A estatuária funerária em Porto Alegre (1900-1950). Dissertação de mestrado, Porto Alegre, Pontifícia Universidade Católica. (mimeo.)

'Algumas considerações sobre o uso da imagem fotográfica na pesquisa antropológica'. Em B. Feldman-Blanco et al., Desafios da imagem: fotografia, iconografia e vídeo nas ciências sociais. Campinas, Papirus.

'Inequality and social class'. Em Sociology as applied to medicine. Londres, Scambler G. Ed.

Indicadores de saúde no Rio Grande do Sul - 1900-1977.

Dissertação de mestrado, São Paulo, Faculdade de Saúde Pública da USP. (mimeo.)

'La pobreza urbana y la salud: una mirada desde la epidemiologia critica'. Em Anais do $1^{\underline{0}}$ Congresso Brasileiro de Epidemiologia. Campinas, Abrasco.

'Enterro de pobre'.

Zero Hora, p. 36.

'Participando do debate sobre mulher e violência'.

Em B. Franchetto (org.), Perspectivas antropológicas da mulher: sobre mulher e violência, vol. 4. Rio de Janeiro, Zahar, pp. 23-62.

Antigualhas - reminiscências de Porto Alegre. Porto Alegre, Companhia União de Seguros Gerais.

Desigualdades na mortalidade infantil entre favelados e não favelados no município de Porto Alegre. Porto Alegre, SSMA.

'Violência no conflito de 1893'. Em M. Flores, 1893-1895: a revolução dos maragatos. Porto Alegre, Edipuc-RS.

Guia bistórico de Porto Alegre. Porto Alegre, Editora da Universidade.

'Iniciação à pesquisa com imagens'. Em B. Feldman-Blanco et al., Desafios da imagem: fotografia, iconografia e vídeo nas ciências sociais. Campinas, Papirus.

O espírito militar na questão acreana — Plácido de Castro. Comissão Nacional do Centenário de Plácido de Castro. Rio de Janeiro, Cia. Brasileira de Artes Gráficas.

'Luto e fotografia'. Em C. Eckert (org.), Imagens em foco: novas perspectivas da antropologia. Porto Alegre, Ed. Universidade.

'Caixões infantis expostos - o problema dos sentimentos na leitura de uma fotografia'. Em B. Feldman-Blanco et al., Desafios da imagem: fotografia, iconografia e vídeo nas ciências sociais. Campinas, Papirus.

História do Brasil.

São Paulo, Ed. Nacional.

'A saúde-doença como processo social'. Em E. Nunes (org.),

Textos de medicina social — aspectos históricos e teóricos. São Paulo, Global. 
Leite, M. M.

1998

Loureiro, S.

1990

Mauch, C. et alii

1994

Masagão, $M$.

1999

Peixoto, C. E.

1998

Rosen, G.

1980

Samain, E.

1998

Singer, P. et alii

1981

Villermé, L. R.

1988

Victora, C. G et alii 1988
'Texto visual e texto verbal'. Em B. Feldman-Blanco et al., Desafios da imagem: fotografia, iconografia e vídeo nas ciências sociais. Campinas, Papirus.

'Brasil — desigualdade social, doença e morte'.

Em Anais do $1^{\circ}$ Congresso Brasileiro de Epidemiologia. Campinas, Abrasco.

Porto Alegre na virada do século XIX: cultura e sociedade.

Porto Alegre/Canoas/São Leopoldo, Edufrgs/Ulbra/Unisinos.

Nós que aqui estamos por vós esperamos.

Documentário, São Paulo, Filmark Distribuidora.

'Caleidoscópio de imagens: o uso do vídeo e sua contribuição à análise das relações sociais'. Em B. Feldman-Blanco et al., Desafios da imagem: fotografia, iconografia e vídeo nas ciências sociais. Campinas, Papirus.

Da polícia médica à medicina social: ensaios sobre a história da assistência médica. Rio de Janeiro, Graal.

Ofotográfico. São Paulo, Hucitec.

Prevenir e curar: o controle social através dos serviços de saúde. Rio de Janeiro, Forense Universitária.

'Reseña del estado fisico y moral de los obreros de las industrias del algodon, la lana y la seda'. Em OPS, El desafio de la epidemiologia - problemas y lecturas selecionadas. Washington D.C., p. 505.

Epidemiologia da desigualdade: um estudo longitudinal de 6.000 crianças brasileiras. São Paulo, Hucitec. 